AperTO - Archivio Istituzionale Open Access dell'Università di Torino

\title{
Unique and common traits in mycorrhizal symbioses
}

\section{This is the author's manuscript}

Original Citation:

Availability:

This version is available http://hdl.handle.net/2318/1758325

since 2020-10-14T13:45:22Z

Published version:

DOI:10.1038/s41579-020-0402-3

Terms of use:

Open Access

Anyone can freely access the full text of works made available as "Open Access". Works made available under a Creative Commons license can be used according to the terms and conditions of said license. Use of all other works requires consent of the right holder (author or publisher) if not exempted from copyright protection by the applicable law. 


\title{
Unique and common traits in mycorrhizal symbioses
}

\author{
Andrea Genre, Luisa Lanfranco, Silvia Perotto and Paola Bonfante ${ }^{\dagger}$ \\ Department of Life Sciences and Systems Biology, University of Turin, Italy. \\ †e-mail: paola.bonfante@unito.it
}

\begin{abstract}
Mycorrhizas are among the most significant biological inter-kingdom interactions, as they involve $\sim 340,000$ land plants and $\sim 50,000$ taxa of soil fungi. In these mutually beneficial interactions, fungi receive photosynthesis-derived carbon and provide the host plant with mineral nutrients such as phosphorus and nitrogen in exchange. Over 150 years of research on mycorrhizas has raised awareness of their biology, biodiversity and ecological impact. In this Review, we focus on recent phylogenomic, molecular and cell biology studies to present the current state of knowledge on the origin of mycorrhizal fungi and the evolutionary history of their relationship with land plants. As mycorrhizas feature a variety of phenotypes, depending on partner taxonomy, physiology and cellular interactions, we explore similarities and differences between mycorrhizal types. During evolution, mycorrhizal fungi have refined their biotrophic capabilities to take advantage of their hosts as food sources and protective niches, while plants have developed multiple strategies to accommodate diverse fungal symbionts. Intimate associations with pervasive ecological success have originated at the crossroads between these two evolutionary pathways. Our understanding of the biological processes underlying these symbioses, where fungi act as biofertilisers and bioprotectors, provides the tools to design biotechnological applications addressing environmental and agricultural challenges.
\end{abstract}

Table of contents blurb ( 50 words max.) 
Mycorrhizas are ubiquitous mutualistic symbioses established between plant roots and soil fungi. In this Review, Bonfante and colleagues explore the origin and evolution of mycorrhizal fungi, the diversity of their interactions with host plants through the identification of common and unique traits, and the potential of application of mycorrhizal symbioses in the development of sustainable agricultural and environmental strategies.

\section{[H1] Introduction}

Mycorrhizas are ubiquitous mutualistic symbioses established between plant roots and soil fungi. Across the intimate cellular contact between the two symbiotic partners, mycorrhizal fungi receive fixed carbon from their photosynthetic hosts in exchange for mineral nutrients, such as phosphorus and nitrogen, with a positive impact on plant growth ${ }^{1}$. The beneficial effect of symbiosis on host plants also includes an increased tolerance to biotic and abiotic stresses ${ }^{2}$. In addition, mycorrhizas offer several ecosystem services in natural and agricultural environments. In fact, mycorrhizal fungi are known drivers of carbon sequestration ${ }^{3}$ and particle aggregation in soil, and have a major impact on the composition of microbial and plant communities ${ }^{4}$. For these reasons, mycorrhizas are believed to have shaped biosphere evolution since plant terrestrialization and, in the current context of growing environmental concerns, they represent crucial actors of ecosystem functioning ${ }^{4,5}$.

Between 320,000 and 340,000 extant vascular and non-vascular plants can form mycorrhizas ${ }^{6}$. Among them, angiosperms account for the largest and most diverse group of mycorrhizal species ( 85-90\%). They include trees, shrubs, herbs and the majority of staple crops such as rice, wheat, maize, potato, sweet potato, tomato and cassava ${ }^{7}$. As for the fungal partners, at least 50,000 fungal species of Ascomycota, Basidiomycota and Mucoromycota are estimated to form mycorrhizas ${ }^{4}$. This startling diversity, supported by over 400 million years of co-evolution between plants and fungi, has generated four main mycorrhizal types that have emerged at different times during plant evolution and feature specific morphological traits: ectomycorrhizas (ECM), arbuscular mycorrhizas (AM), orchid mycorrhizas (ORM) and ericoid mycorrhizas (ERM; Fig. 1). Cell-to-cell interactions in each mycorrhizal type 
(Box 1) have fascinated plant biologists since the pioneering ultrastructural observations in the $1980 \mathrm{~s}^{8,9}$ and set the foundation for subsequent investigations on signaling and gene regulation in these symbioses.

Mycorrhizas are formed by the majority of plants, but display an uneven distribution: AM are the dominant type (72\%), followed by ORM (10\%), ECM (2\%) and ERM $(1.4 \%)^{6}$. Multiple mycorrhizal types co-exist in many ecosystems, with plant and fungal species establishing - in some cases - more than one mycorrhizal type (Fig. 1). In addition, a single fungus can colonize different hosts, establishing a 'common mycorrhizal network' (Fig. 1), that is, an underground hyphal network connecting distinct plant individuals ${ }^{10}$.

Mycorrhizal fungi are now considered among the dominant components of the plant microbiota ${ }^{11}$, the biodiverse ecosystem of microbial communities that live in close association with multicellular individuals and impact plant health ${ }^{12,13}$. In this context, mycorrhizal fungi could act as drivers of the so-called Microbial Revolution, that is, the development of sustainable, microbiome-based tools to enhance plant health and productivity.

In this Review, we explore the biological diversity of mycorrhizas, which have historically been grouped according to their morphological features (Box 1), through the identification of unique and common traits between types. Fossil data and phylogenomic studies offer an evolution-based guideline to illustrate how ancient saprotrophic fungi feeding on decaying organic matter evolved a novel nutritional strategy based on biotrophism . Furthermore, we discuss how fungal biotrophism is supported by multiple signalling and colonization processes, underpinned by relatively conserved genetic bases in plants. Lastly, we outline the potential of mycorrhizal symbioses as important actors in a global scenario that calls for the increasing use of sustainable agricultural and environmental strategies (Box 2).

\section{[H1] Origin and evolution of mycorrhizas}

Due to their importance in ancient and extant ecosystems, the evolution of mycorrhizas has been explored in several reviews on the basis of data from palaeontology, genomic and phylogenomic studies, as well as plant and fungal 
diversity ${ }^{6,14,15}$, with the final aim to decipher the origin of their pervasive ecological success.

The earliest fossil evidence of plant-fungus associations is in the 407 million year old Rhynie chert, where rhizomes of extinct plants like Aglaophyton majus hosted arbuscule-like structures. These structures are similar to the AM observed in extant plant roots $^{16}$ (Box 1), suggesting that the AM symbiosis has played a role in land colonization by the earliest plants. Liverworts are the earliest diverging group among living plants and the occurrence of AMs in extant species (Fig. 2) supports this hypothesis, even though mycorrhizal fossils of these non-vascular plants have not been found. Rhynie chert specimens suggest that AM fungi assigned to the subphylum Glomeromycotina ${ }^{17}$ were not alone in colonizing the first land plants, as additional intracellular fungi morphologically similar to extant Mucoromycotina have been found ${ }^{18}$. Indeed, phylogenomic evidence places the origin of both Mucoromycotina and Glomeromycotina (AM fungi) in the mid-late Silurian, $\sim 420$ million years ago (MYA) ${ }^{17,19,20,21}$.

Even though the origin of ECM (Fig.1 and Box 1) likely correlates with the appearance of Pinaceae (gymnosperms), between 170 and $270 \mathrm{MYA}^{14}, \mathrm{ECM}$ fossils are more recent and date back to 52 MYA, in the early Eocene ${ }^{22}$. The Gnepine hypothesis suggests that Gnetales are a sister group of Pinaceae ${ }^{23}$, and it is interesting that members of the genus Gnetum also bear ECM. However, other Gnetales (Welwitschia and Ephedra genera) are AM plants, as well as the remaining gymnosperms, including the 'living fossil' Ginkgo biloba. These data indicate that only some gymnosperms lost their primal AM status to embrace ECM, possibly under the pressure of environmental constraints. In general terms, the dominance of AM symbiosis in angiosperms mirrors the ecological success of this lineage since its evolutionary burst 140-180 MYA. Major exceptions are represented by Orchidaceae and Ericaceae, two families that developed different mycorrhizal interactions. Convincing fossils of ORM are currently not available (Box 3), but their appearance must follow the late Cretaceous origin (76-84 MYA) of this family ${ }^{24}$. ERM developed in the Ericaceae from $A M$ ancestors ${ }^{25}$ and their most ancient fossils, belonging to the extant genus Leucothoe, date from 66-72 MYA ${ }^{14}$. 
Despite the discontinuity of the fossil record, mycorrhizal interactions likely evolved in non-vascular ancestors of extant plants with the instrumental role of favoring plant nutrient acquisition from the harsh primeval soils. In this regard, the limited occurrence of mycorrhizal interactions in extant early diverging plants (Bryophytes) appears puzzling. Mycorrhizas are in fact absent in mosses (including the model species Physcomitrella patens) and are found rather erratically in hornworts ${ }^{6}$ and liverworts (Fig. 2), where the congeneric Marchantia paleacea and M. polymorpha are mycorrhizal and non-mycorrhizal, respectively ${ }^{26}$. A recent survey revealed that less than $30 \%$ of the examined liverworts engage associations with symbiotic fungi and those with Glomeromycotina are particularly few ${ }^{27}$. However, a limited number of species have been examined so far. Similarly, AM fungi are not dominant among early-diverging tracheophytes like ferns and club mosses ${ }^{6,28}$. A clue to this conundrum may come from the observation that photosynthesis and growth promotion in $\mathrm{AM}$ liverworts are enhanced under high $\mathrm{CO}_{2}$ conditions ${ }^{29}$, resembling those of the Paleozoic atmosphere. It is therefore tempting to speculate that the progressive reduction in atmospheric $\mathrm{CO}_{2}$ concentration during more recent geological eras eroded the usefulness of AM in some of these early diverging plants. Biosphere evolution can therefore be added to some more obvious ecological considerations: in particular, bryophytes live in very humid environments and in close contact with the wet soil surface, possibly reducing the need for AM fungi as suppliers of water and minerals. On the other hand, the preference of seed plants (gymnosperms and angiosperms ) for AM may reflect the positive impact of mycorrhizal symbiosis on seed quality. In fact, studies on crop plants such as maize and wheat have demonstrated that mycorrhizal plants have larger seeds with a higher nutritional content ${ }^{30,31}$. This observation alone suggests a direct transgenerational effect with obvious implications in the success of mycorrhizal seed plants $^{32,33}$.

\section{[H1] Evolutionary trends in mycorrhizal fungi}

Mycorrhizal fungi are highly diverse in terms of their evolutionary history. However, genome sequencing of a substantial number of fungal species (see the fungal 
genomic resource MycoCosm ()) suggests that mechanisms of convergent evolution may have shaped their genomes. The most notable trait shared by all mycorrhizal fungi is the expansion of small secreted protein families that may act as effectors (Fig. 3) to manipulate host responses and to facilitate mutualistic interactions ${ }^{34}$. However, this genomic feature is also found in other plant-interacting microorganisms, like plant pathogens, where effector functions have been extensively characterized ${ }^{35,36}$. In addition, a limited complement of plant cell wall degrading carbohydrate-active enzymes (CAZymes) characterizes the evolutionarily oldest $\mathrm{AM}$ and $\mathrm{ECM}$ fungi ${ }^{34,37}$. In saprotrophic fungi, plant cell wall degrading enzymes are instrumental for the degradation of the organic soil litter. Whereas no data exists to support the origin of AM fungi from saprotrophic CAZyme-equipped ancestors, phylogenomic reconstructions clearly show that Basidiomycota ECM fungi evolved independently from saprotrophs, mainly wood decaying white and brown rot fungi, that possessed genes for lignin and/or cellulose degradation ${ }^{38,39}$. In most cases, the ECM lifestyle favored the loss of genes involved in the of lignocellulose and phenolic compounds present in soil organic matter ${ }^{40}$. However, the degree to which individual ECM species have maintained saprotrophy-related genes differs among lineages ${ }^{37}$, likely reflecting their evolutionary history and specific ecological functions, such as the ability to provide host plants with organic matter-derived nitrogen $^{41}$. Genome sequencing of Pezizomycotina ECM, such as the widespread Cenoccoccum geophilum ${ }^{42}$ and several truffles belonging to the Tuberaceae ${ }^{43}$, also revealed a reduction in lignocellulose-degrading enzymes in Ascomycota.

Irrespective of their evolutionary history, the small complement of CAZymes in AM and ECM suggests that fungal colonization of plant tissues may be largely modulated by the host plant, according to its nutritional needs and physiological status. Notably, the poor ability of fungi to degrade plant cell wall polysaccharides would also limit the release of degradation by-products, which are potent elicitors of plant defence ${ }^{44}$. In contrast with such apparently similar evolutionary trends in AM and ECM (Fig. 2), a surprisingly large set of cell wall degrading enzymes was found in the genomes of ORM and ERM fungi ${ }^{37}$. Their occurrence in ORM fungi like the Agaricomycetes Serendipita vermifera (order Sebacinales) and Tulasnella calospora (order Cantharellales) aligns with the role of these fungi in plant nutrition. In the early 
stages of their development, orchids are heterotrophic and ORM fungi feed them with carbohydrates likely extracted from soil organic matter ${ }^{1}$. Beside polysaccharidedegrading enzymes, the genomes of ERM Ascomycetes Oidiodendron maius and Rhizoscyphus ericae also contain numerous lipases, proteases and secondary metabolism enzymes, much like saprotrophs and non-mycorrhizal fungal endophytes ${ }^{45,46}$. Overall, the genomic features of phylogenetically distant ORM and ERM fungi, where a large suite of small secreted proteins (likely involved in their interactions with hosts) associate with an array of cell wall degrading enzymes (Fig. 3), mirror their dual biotrophic and saprotrophic capabilities. This may be the result of an evolutionary incomplete transition from the saprotrophic to the mycorrhizal habit $^{34,37}$, likely due to the recent origin of these symbioses, both found exclusively in angiosperm taxa. However, some ECM lineages also originated quite recently but underwent a strong reduction in CAZymes. For example, molecular data indicate that ECM fungal lineages in the Laccaria genus have diversified from saprotrophic ancestors $~ 56-66 \mathrm{MYA}^{48}$, whereas phylogenomics placed the origin of ERM fungi 118 MYA, about the same time proposed for the origin of the family Ericaceae ${ }^{45}$. A more intriguing hypothesis to explain the genomic features of ERM and ORM fungi, in contrast to those of $A M$ and ECM fungi, derives from the observation that specialization to narrow ecological niches commonly leads to gene loss ${ }^{49}$. Thus, one could hypothesize that AM (and to a lesser degree ECM) fungi evolved as exclusive mycorrhizal symbionts with the loss of specific genes, whereas ERM and ORM fungi retained a much broader ecological niche $e^{4,47}$, which allows them to switch between saprotrophic (in soil), mycorrhizal (in roots) and even pathogenic strategies ${ }^{46}$.

Genome sequencing of AM fungi has provided clues to explain their peculiar status of obligate biotrophs and several of their characteristic functional traits. Different AM fungal species feature an overall comparable number of genes spread over very large genomes rich in transposable elements, ranging from $125 \mathrm{Mb}$ in Rhizophagus irregularis to $770 \mathrm{Mb}$ in Gigaspora margarita ${ }^{50,51}$. Phosphate uptake was established as the most iconic feature of AM fungi since the earliest studies on symbiosis functioning ${ }^{52}$, but only the recent sequencing of the G. margarita genome has revealed an expansion of phosphate metabolism-related genes, supporting the key role of these fungi as biofertilizers ${ }^{51}$. Some genome erosion has also occurred and all 
sequenced AM fungi lack a few basic metabolic processes, such as fatty acid and thiamine (also known as vitamin $B_{1}$ ) biosynthesis. The absence of fatty acid synthase $^{53}$ inspired the recent discovery that AM fungi - characterized by the extensive accumulation of reserve lipids - are fatty acid auxotrophs and rely on lipids received from the host plant ${ }^{54,55}$. Although tracing back the ancestors of AM fungi is not an easy task, Glomeromycotina cluster with the lipid-rich but predominantly saprotrophic Mortierellomycotina and Mucoromycotina ${ }^{17,21}$. Crucial information on a potential saprotrophic origin will come from genome sequencing of the earliest diverging taxa of Glomeromycotina, including Geosyphon pyriforme, a non-AM fungus that associates with photosynthetic cyanobacteria ${ }^{56}$.

In conclusion, fungal phylogenomics provides a first insight into the evolution of mycorrhizal fungi that fits with the fossil record (Box 3). These data identify Glomeromycotina and/or Mucoromycotina ${ }^{21}$ as the most ancient mycorrhizal fungi and highlight biotrophism as a common trait that resulted from different evolutionary pathways.

\section{[H1] Symbiotic signatures}

Regardless of the taxonomy, origin and evolutionary history of mycorrhizal fungi, host plants have represented a common challenge to all plant-interacting fungi. Studies focused on AM plants have revealed that a core set of genes is necessary to establish symbiosis ${ }^{57}$ and that this plant symbiotic 'toolkit' is conserved across plant taxa ${ }^{58,59}$. This genetic signature includes members of the so-called common symbiotic signaling pathway (CSSP), namely SYMRK, CCAMK and CYCLOPS, that are conserved in all AM host species ${ }^{59,60,61}$ and are also required for the establishment of symbiotic nitrogen fixation in legumes ${ }^{57}$ and actinorhizal plants ${ }^{62}$. Unexpectedly, a few of these genes occur in charophytes, the closest living algal relatives of land plant ancestors ${ }^{58}$. The absence of known mycorrhizal-like interactions in algae opens several intriguing questions about the function of 'symbiotic' genes in charophytes and the process by which this set of genes has been exapted for new functions in early plants ${ }^{58}$. This symbiotic toolkit also includes transcription factors that coordinate the expression of a set of downstream plant genes involved in specific symbiotic functions, such as phosphate transport and lipid synthesis and transport ${ }^{59}$. 
Plant phylogenomics and functional analysis of the symbiotic toolkit have been instrumental for the identification of this gene hierarchy in AM hosts ${ }^{63}$.

The fungal symbiotic toolkit appears to have followed a different evolutionary trajectory. Transcriptomic analyses in ECM revealed that many fungal symbiotic genes, that is those up-regulated in mycorrhizal roots, are restricted to a single fungal species ${ }^{37}$. Indeed, the majority of symbiosis-induced genes do not have homologs between Laccaria amethystina and L. bicolor, that diverged only around 20 MYA. Also, the comparison across AM species of expressed candidate secreted proteins, expected to play a key role in plant-fungus interactions ${ }^{35,36}$, revealed the prevalence of lineage-specific proteins ${ }^{64}$. Remarkably, the expression of some of these secreted proteins can even differ within the same AM species, depending on the host plant ${ }^{64}$. Genomics data also point to large differences in the gene repertoire of closely related $\mathrm{AM}$ fungal species ${ }^{50,51}$. Although the majority of these genes has not been characterized, these observations indicate that lineage-specific genes with possible roles in symbiosis have evolved several times in the genome of mycorrhizal fungi, even over a relatively short evolutionary timescale $37,51,64$. Consequently, distinctive features of symbiotic fungi are not limited to the convergent loss of CAzymes - at least for AM and ECM - but also include the evolution of lineagespecific functional innovations.

In addition to the necessary genetic toolkits, symbiotic partners need to sense each other in the soil, and signal exchange is an essential step in the development of mycorrhizal symbioses. Such presymbiotic chemical dialogue has been studied more deeply in AM, where a number of molecules have been characterized as reciprocally active symbiotic signals ${ }^{65}$. Host plant roots actively exude strigolactones ${ }^{66,67}$, a class of apocarotenoids that are sensed by AM fungi and promote spore germination, hyphal branching, nuclear divisions and respiratory metabolism ${ }^{68,69}$. With respect to fungi, a few chitin-derived molecules (or Myc-factors) have been identified in AM fungal exudates as biologically active signals ${ }^{70,71}$ triggering the CSSP in the host plant. Such Myc-factors include chito-oligosaccharides (COs) made of four to five $\mathrm{N}$ acetylglucosamine residues $^{71,72,73}$ as well as lipo-chitooligosaccharides (LCOs) ${ }^{70}$, where a fatty acid chain and/or a sulphate group are bonded to the oligosaccharidic chain. The sensing of COs and LCOs by the host plant ${ }^{74}$ activates responses that 
prepare the plant for fungal colonizationand range from the regulation of symbiosissupporting genes ${ }^{75,76,77}$ to physiological, metabolic and developmental changes on a cellular, organ and organismal scale ${ }^{78,79,80}$.

Our knowledge of presymbiotic signaling in other mycorrhizal interactions remains limited. Molecules acting as presymbiotic signals have not been identified in ERM and ORM, but the key genetic components of the plant CSSP have been identified through homology searches in the genome of some orchid species ${ }^{81,82}$ and in the root transcriptome of the ERM species Rhododendron fortunei ${ }^{59}$. These findings, together with the ability of the CCaMK gene of the orchid Bletilla striata to restore both AM and nodule formation in a CCaMK-defective Lotus japonicus mutant ${ }^{81}$, suggest a wide conservation of the CSSP across plants forming different mycorrhizal types. Interestingly, some genes involved in early signaling, including key genes for strigolactone biosynthesis and secretion, are present in multiple copies in the genome of Gastrodia elata, a non-photosynthetic orchid that strictly depends on its ORM fungus for nutrients ${ }^{82}$. This condition may increase the ability of G. elata to interact with the ORM fungal partner and to establish the symbiotic relationship ${ }^{82}$. Molecules acting as ECM presymbiotic signals have been recently identified ${ }^{83}$ in the ECM fungus L. bicolor, which releases a cocktail of LCOs able to activate the CSSP in poplar roots. However, CSSP conservation in poplar is likely related to its ability to also host AM fungi. Indeed, a comparative analysis of over 120 plant genomes and 270 transcriptomes $^{59}$ demonstrated that a broad set of genes (not limited to CSSP members) is conserved in all plant lineages hosting intracellular symbionts including $A M$, ORM, ERM as well as nitrogen fixing symbioses - but has been lost several times during the evolution of lineages hosting extracellular symbionts (including ECM and cyanobacterial associations) or those that are plainly nonsymbiotic (Fig. 3).

In conclusion, the CSSP is emerging as a key pathway regulating all endomycorrhizal interactions. A few observations suggest a more general role, at least for individual CSSP members. In particular, L. japonicus CCamK and SymRK, or their orthologs in other species, were found to play a role in plant responses to beneficial microorganisms ${ }^{84}$, nematodes ${ }^{85}$, parasitic plants ${ }^{86}$, fungal endophytes ${ }^{87}$, pathogenic fungi ${ }^{88}$ and thigmotropic stimuli ${ }^{85,89}$. These observations point to additional roles for 
individual CSSP members, in agreement with their presence in the genomes of charophytes, where their function has unfortunately not been characterized ${ }^{20,58}$.

\section{[H1] Plant-fungus interfaces and colonization}

Following reciprocal signaling and recognition, the sub-apical region of young lateral roots is the most common site of plant-fungus contacts ${ }^{8}$. The broad developmental plasticity and responsiveness of this area may be a major requirement for symbiont accommodation. An even more pronounced plasticity can be envisaged for postembryonic cells of orchid protocorms in ORM (Box 1).

Intriguingly, AM fungi are the only known fungal symbionts to develop a specialized adhesion structure - the hyphopodium ${ }^{90}$. This broad and often branched expansion of the hyphal tip represents a substantial resource investment by the fungus and generates a large contact surface with epidermal cells. Its development may be related to the inability of AM fungi to actively pierce the plant cell wall enzymatically and the consequent need to elicit accommodation responses in the host (including prepenetration apparatus assembly and local cell wall loosening under the hyphopodium). In fact, epidermal cell penetration occurs several hours after the partner contact ${ }^{91}$, in contrast with the direct penetration of epidermal cell walls by both ERM and ORM, both of which express numerous plant cell wall degrading enzymes during interaction with the plant ${ }^{37,45}$.

In ECM, extensive hyphal proliferation between and beneath epidermal cells is associated with a weakening of plant cell wall cohesion. Fungal colonization of the resulting apoplastic space is believed to depend on the chemical degradation of middle lamella pectins, combined with mechanical forces developed by hyphal tip growth $^{34,92}$. Notably, in L. bicolor this process was recently shown to be enhanced by a symbiosis-induced endoglucanase (LbGH5-CBM1) ${ }^{93}$.

In all cases, a substantial amount of fungal mycelium, either intercellular, as in ECM, or in the very lumen of individual plant cells, as in AM, ERM and ORM, is accommodated within the host tissues. This implies a massive reprogramming of plant development in coordination with fungal growth. In the case of ECM, this reprogramming primarily involves root meristems, which initially generate a novel pattern of recursive dichotomous branching and eventually stop their activity as the 
fungal mantle envelops them ${ }^{34}$. Alterations of root auxin signaling by the colonizing ECM fungus have been proposed to play a major role in these developmental processes, even if a consistent model is still missing ${ }^{94}$. Extensive root branching has been observed in both ERM and AM since the earliest interaction with the symbiotic fungi. However, the most striking developmental changes characterizing all endomycorrhizal interactions (AM, ERM and ORM) take place inside the colonized cells, with the appearance of de novo assembled cell compartments containing cell wall components that are lined by the host cell membrane (Box 1).

A common feature emerging from this scenario is that symbiotic fungal hyphae never have direct access to the host cell cytoplasm and they are confined to the apoplastic space within diverse symbiotic interfaces. These interfaces are also the main sites of nutrient exchange, thus representing the functional core of all mycorrhizal symbioses. In AM, the generation of a symbiotic interface seems to be dependent on CSSP signaling ${ }^{78,95}$, in striking analogy with other plant symbioses, such as symbiotic nitrogen fixation and actinorrhizas ${ }^{62}$. The numerous structural similarities observed among AM, ERM and ORM, as well as the induction of many homologs of $\mathrm{AM}$-induced genes in $\mathrm{ORM}^{81,96,97}$, hint at the possible use of similar signaling and developmental processes across endomycorrhizal interactions. Furthermore, the development of apoplastic interfaces is common to several other plant-microorganism interactions, ranging from the infection thread in legumerhizobium symbiosis ${ }^{98}$ to actinorrhizal interactions ${ }^{99}$, to less characterized bacterial and fungal endophytic associations ${ }^{100,101}$ and the more studied biotrophic pathogenic interactions ${ }^{102,103}$. At least some of the plant cell responses may be conserved among all such diverse interactions ${ }^{85,104}$, but further investigations are needed before a global model of microorganism accommodation processes in plants can be outlined.

\section{[H1] Strategies for successful colonization}

To sustain such an intimate functional association, mycorrhizal colonization requires a reprogramming of the whole plant metabolism. Extensive plant gene expression modulation was described in AM plants with up to thousands of differentially expressed genes, mirroring the deep cellular reorganization upon fungal entry ${ }^{31,75,77}$. 
A few of these genes (such as the Medicago truncatula phosphate transporter MtPT4) have been identified as AM-specific and are currently used as markers of symbiosis functionality. By contrast, in ECM roots, gene expression was found to be more extensively regulated in the fungus (up to $20 \%$ of the analysed transcripts) than in the plant (2-5\% of the transcripts) ${ }^{105,106}$. On the same line, ECM development has not been associated with the expression of symbiosis-specific plant marker genes.

Since the first transcriptomic studies of both AM and ECM, particular interest was raised by genes involved in plant defence. Cell wall components of mycorrhizal fungi can indeed be perceived by the host plants as microbe-associated molecular patterns (MAMPs) and elicit plant immune responses ${ }^{107}$. The transient activation of such defence responses during early AM formation has been detected in several studies $^{108,109,110,111}$. This activation has been explained as a form of plant priming ${ }^{112}$ that contributes to the so-called mycorrhiza-induced resistance (MIR) and leads to higher resistance of AM plants to biotrophic and necrotrophic pathogens, nematodes, insects and viruses ${ }^{31,113,114,115}$.

Among MAMPs, chitin-related molecules have a pivotal role as elicitors of the plant response. Even if the picture is far from clear, such chitin-based signals have been shown to trigger different plant responses depending on the length of their chitinous backbone. Short-chain chitin oligomers (tetra- and pentamers) are potent elicitors of the CSSP in all AM hosts tested so $\mathrm{far}^{70,71,72}$ - a function that in legumes is also played by chitin oligomer derivatives bearing lateral substitutions such as sulphate groups and a lipid tail ${ }^{64,52}$. By contrast, longer molecules (such as chito-octamers) activate pathogen-associated molecular pattern-triggered immunity (PTI) ${ }^{107}$, mitogen-activated protein kinase signaling, reactive oxygen species release and defence gene expression ${ }^{116,117}$. Indeed, recent studies in rice have demonstrated that the same LysM receptor-like kinase, OSCERK1, is involved in either symbiotic or pathogenic signal perception ${ }^{118,119}$, likely depending on the cohort of co-receptors that discriminate between long and short chitin chains ${ }^{65,74,120}$. One study discovered an important element to this scenario, revealing that a secreted fungal protein (RiSLM) with high affinity for long chain chitin molecules can play a role in sequestering and masking such pathogen-like molecules, thus promoting recognition of symbiotic signals in AM fungal exudates ${ }^{121}$. 
Early plant responses to ECM fungi also involve nonspecific, broad-spectrum defences, including increased chitinase and peroxidase activities during hyphal penetration into the apoplastic space of the root cortex. This pattern is attenuated in

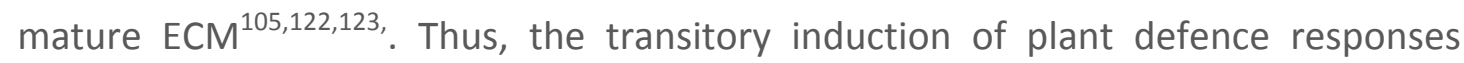
appears to be shared between AM and ECM; in both, plant hormone signals have been proposed to play a major role $\mathrm{e}^{34,124,125}$.

Fungal effectors are emerging actors in the molecular mechanisms modulating plant responses and a large repertoire of putative effectors has been identified in $\mathrm{AM}^{50,64,126,127,128,129}$ and $\mathrm{ECM}$ fungal genomes or transcriptomes ${ }^{37,42,43,125}$. A few of these effectors have been demonstrated to enter the host cell and interfere with gene regulation. A seminal study ${ }^{129}$ provided the first evidence of translocation of an AM fungal protein (SP7) into the plant cell nucleus, where it was suggested to counteract the plant immune response by interacting with a pathogenesis-related transcription factor. Another AM effector (RiCRN1) was also recently shown to localize in plant host nuclei and to be crucial for symbiosis progression and arbuscule development ${ }^{130}$. Concerning ECM, the Laccaria bicolor MiSSP7 effector was proposed to interfere with plant immunity by repressing jasmonic acid-responsive genes ${ }^{125}$. Although several small secreted proteins that may act as effectors were identified in the genomes of ERM and ORM fungi $\mathrm{i}^{37,45}$, only a hydrophobin-like protein was characterized in the ERM fungus $O$. maius ${ }^{131}$, but its mechanism of action remains unknown.

This overview of plant and fungal strategies supporting mycorrhizal establishment highlights a few common traits (Fig. 3). Strikingly, some of these molecular tools (such as MAMPs and effectors) and processes (pattern- and effector-triggered immunity) are also fundamental during pathogenic interactions. The current challenge is to decipher the regulatory networks that discriminate between plant responses activated upon pathogen attacks from those allowing the establishment of a long-lasting beneficial interaction with mutualistic symbionts. This knowledge will be instrumental in understanding how mycorrhizal fungi regulate plant immunity and behave as additional layers of defence against biotic stresses ${ }^{132}$.

\section{[H1] Conclusions and outlook}


Our bird's eye view of mycorrhizal interactions highlights the morphological diversity of mycorrhizal types developed by $\sim 340,000$ plant species, with functions that largely reflect the metabolic and ecological capabilities of theirfungal partners. Notwithstanding the individual evolutionary history of each plant taxon, the mycorrhizal status seems to stem from common genetic bases already present in the common ancestor of land plants. The coevolution of land plants with AM fungi was revealed by fossil reports and is acknowledged as a dogma among plant biologists, but plant-fungal coevolution can also be hypothesized for the other more recent mycorrhizal types. Thanks to a number of independent evolutionary events, a few gymnosperm and angiosperm taxa, such as Pinaceae (170-270 MYA) and rosids (100-109 MYA), started to establish ECM interactions with fungi that had lost ancient saprotrophic strategies - including lignin decaying capabilities - in order to grant cell viability to their hosts ${ }^{4}$. Plant-fungus coevolution in ORM has likely been shaped by the peculiar nutritional strategies of orchids. In fact, ORM fungi ensure the ecological success of members of this large plant family by feeding them with organic carbon during early plant development, if not along the whole life cycle of the numerous achlorophyllous species ${ }^{133}$. Although ERM plants interact with a relatively small number of fungal taxa, a possible coevolution in this symbiosis is less clear because of the broad ecological niche of most fungal partners.

The low frequency of mycorrhizal associations in early diverging plants, such as bryophytes and pteridophytes, remains enigmatic. Marchantia paleacea and $M$. polymorpha appear an ideal system for comparative 'omics investigations to shed light on their different attitude towards symbiotic fungi, and phylogenomics of early diverging plants is expected to provide a broader picture. Even though fungal genome sequencing has identified key players in the interaction, such as secreted effectors, AM fungi unfortunately remain beyond reach for genetic approaches, and although a few species of mycorrhizal Ascomycota and Basidiomycota are amenable for genetic transformation, a limited number of functional studies has been published.

In the context of environmental global changes, the influence of the anthropogenic impact on mycorrhizal establishment and functioning has not been fully understood. For example, high phosphate availability, which is the expected condition in intensive 
agriculture, inhibits AM establishment ${ }^{134}$, probably affecting early signaling events. On the other hand, soil contaminants, resulting from industrial activities, may lead to the selection of heavy metal-tolerant fungi that could potentially be more successful in their symbiotic performance ${ }^{175}$. These examples suggest that environmental conditions may overcome the genetic blueprint of both the partners as a major determinant of symbiosis development and functioning, and urge for further investigations.

Although mycorrhizal interactions occur in the roots of higher plants, their benefits extend to the whole individual, and even to its progeny, through the impact of symbiosis on seed production and quality. Such systemic effects are at the basis of the well-known 'growth effect' described in mycorrhizal interactions: the characterization of plant mechanisms underlying such systemic effects, such as phytohormone, miRNAs or peptide based signalling ${ }^{135}$ for all mycorrhizal types is a crucial challenge for future research in this field. We envisage that the growing number of studies based on big data, implementation of models and correlation networks, are bound to provide new clues and lead the way to new research avenues addressing the biological and ecological complexity of mycorrhizal interactions and novel strategies for agricultural applications in a changing environment.

\section{Acknowledgements}

The authors apologize to colleagues whose work could not be cited due to space limitations. The authors are grateful to Alessandro Desirò for agreeing to share Fig. 2 and to Dan Chamberlain and Jennifer Mach for language editing. Contributions to this Review have been partially funded by Fondazione Cassa di Risparmio di Cuneo (Bando Ricerca Scientifica 2015 - Project AM-FOR-Quality) and by the European Union's Horizon 2020 research and innovation programme under grant agreement $N^{\circ} 727929$ (TOMRES).

\section{Author contributions}

The authors contributed equally to all aspects of the article. 


\section{Competing interests}

The authors declare no competing interests.

\section{Peer review information}

Nature Reviews Microbiology thanks K. Field and the other, anonymous, reviewer(s) for their contribution to the peer review of this work.

\section{Publisher's note}

Springer Nature remains neutral with regard to jurisdictional claims in published maps and institutional affiliations.

\section{Related links}

MycoCosm

\section{Glossary}

Angiosperms: vascular plants with seeds and flowers; they are the largest and most diverse group within the kingdom Plantae

Auxotrophy: the inability of an organism to synthesize a particular organic compound required for its growth

Biotrophism: the nutritional strategy of a pathogen or a mutualist that needs its host in order to stay alive

Bryophytes: the term refers to an informal group of early diverging, non-vascular plants, consisting of three divisions: liverworts, hornworts and mosses. All of them are characterized by a dominant ganethophytic phase

Cyanobacteria: a group of nitrogen-fixing bacteria forming filamentous colonies arranged in a gelatinous sheath.

Gnepine Hypothesis: according to this hypothesis on the evolution of Gymnosperms, Gnetophytes are a sister group to Pinaceae.

Gymnosperms: a group of vascular, non-flowering seed-producing plants that includes among the others conifers, cycads, and Ginkgo biloba.

Hornworts: see Bryophytes. 
Liverworts: commonly referred to as hepatics, see Bryophytes

Meristem: a plant tissue consisting of proliferating stem cells (meristematic cells) that generate tissues and organs.

Protocorm: an intermediate tuber-like structure derived from the embryo after germination of orchid seeds and before seedling development

Rhynie chert: an Early Devonian sedimentary deposit located in Scotland and exhibiting exceptionally well preserved fossils of plants, fungi, lichens and animals from an early terrestrial ecosystem.

Saprotrophism: nutritional strategy common to most fungi and bacteria, based on the extracellular degradation of dead organic matter.

Thigmotropism: a directional growth occurring as a mechanosensory response to a touch stimulus.

\section{References}

1. Smith, S.E. \& Read, D. Mycorrhizal Symbiosis, 3rd edition (Academic Press, London, 2008).

2. Bahadur, A. et al. Mechanistic insights into arbuscular mycorrhizal fungimediated drought stress tolerance in plants. Int. J. Mol. Sci. 20, E4199 (2019).

3. Johnson, N., Gehring, C. \& Jansa, J. Mycorrhizal mediation of soil (Elsevier, 2016).

4. van der Heijden, M.A., Martin, F. M., Selosse, M-A. \& Sanders, I. R. Mycorrhizal ecology and evolution: the past, the present, and the future. New Phytol. 205, 1406-1423 (2015).

5. Ferlian, O. et al. Mycorrhiza in tree diversity-ecosystem function relationships: conceptual framework and experimental implementation. Ecosphere 9, e02226 (2018).

6. Tedersoo, L., Bahram, M. \& Zob, M. How mycorrhizal associations drive plant population and community. Science, 367, eaba1223 (2020).

7. Fernie A.R. \& Yan J. De novo domestication: an alternative route toward new crops for the future. Mol. Plant. 12, 615-631 (2019).

8. Peterson, R. L., Massicotte, H. B., \& Melville, L. H. Mycorrhizas: Anatomy and Cell Biology(CABI Publishing, Oxon, 2004).

9. Bonfante, P. The future has roots in the past: the ideas and scientists that shaped mycorrhizal research. New Phytol. 220(4), 982-995 (2018). 
10. Simard, S. W. et al. Mycorrhizal networks: Mechanisms, ecology and modelling. Fung. Biol. Rev. 26(1), 39-60 (2012).

11. Bonfante, P., Venice, F. \& Lanfranco L. The mycobiota: fungi take their place between plants and bacteria. Curr. Opin. Microbiol. 49, 18-25 (2019).

12. Compant, S., Samad, A., Faist, H. \& Sessitsch, A. A review on the plant microbiome: Ecology, functions, and emerging trends in microbial application. J. Adv. Res. 19, 29-37 (2019).

13. Elinav, E., Garrett, W.S., Trinchieri, G. \& Wargo, J. The cancer microbiome. Nature Rev. Cancer 19, 371-376 (2019).

14. Strullu-Derrien, C., Selosse, M. A., Kenrick, P. \& Martin, F.M. The origin and evolution of mycorrhizal symbioses: from palaeomycology to phylogenomics. New Phytol. 220(4), 1012-1030 (2018). This review is a precious resource of data linking fossil reports with fungal genome sequences

15. Field, K. J. \& Pressel, S. Unity in diversity: Structural and functional insights into the ancient partnerships between plants and fungi. New Phytol. 220, 996-1011 (2018).

16. Remy, W., Taylor, T. N., Hass, H. \& Kerp, H. Four hundred-million-year-old vesicular arbuscular mycorrhizae. Proc. Natl. Acad. Sci. USA 91, 11841-11843 (1994).

17. Spatafora, J. W. et al. A phylum-level phylogenetic classification of zygomycete fungi based on genome-scale data. Mycologia, 108(5), 1028-1046 (2016).

18. Strullu-Derrien, C. et al. Fungal associations in Horneophyton ligneri from the Rhynie Chert (c. $407 \mathrm{Ma}$ ) closely resemble those in extant lower land plants: novel insights into ancestral plant-fungus symbioses. New Phytol. 203, 964-979 (2014).

19. Feijen, F.A.A., Vos, R.A., Nuytinck, J. \& Merckx, V. S. F. T. Evolutionary dynamics of mycorrhizal symbiosis in land plant diversification. Sci. Rep. 8, 10698 (2018).

20. Hoysted, G. A. et al. A mycorrhizal revolution. Curr. Opin. Plant Biol. 44, 1-6 (2018).

21. Bonfante, P. \& Venice, F. Mucoromycota: going to the roots of plantinteracting fungi. Fung. Biol. Rev. (2020)

22. Beimforde, C. et al. Ectomycorrhizas from a Lower Eocene angiosperm forest. New Phytol. 192, 988-996 (2011).

23. Jin-Hua R., Shen, T.T., Wang, M. M. \& Wang X. Q. Phylogenomics resolves the deep phylogeny of seed plants and indicates partial convergent or homoplastic evolution between Gnetales and angiosperms. Proc. R. Soc. 285, 20181012 (2018)

24. Ramirez, S. R., Gravendeel, B., Singer, R. B., Marshall. C. R. \& Pierce, N. E. Dating the origin of the Orchidaceae from a fossil orchid with its pollinator. Nature 448, 1042-1045 (2007).

25. Freudenstein, J. V., Broe, B. B. \& Feldenkris, E. R. Phylogenetic relationships at the base of Ericaceae: implications for vegetative and mycorrhizal evolution. Taxon 65, 794-804 (2016).

26. Ligrone, R. et al. Glomeromycotean associations in liverworts: a molecular, cellular, and taxonomic analysis. Amer. J. Bot. 94(11), 1756-1777 (2007). 
27. Rimington, WR., Duckett, JG , Field, KJ, Bidartondo, MI, Pressel, S. The distribution and evolution of fungal symbioses in ancient lineages of land plants. Mycorrhiza 29, 551-565 (2020).

28. Benucci, GM. et al. Evidence for co-evolutionary history of early diverging Lycopodiaceae plants with fungi. Front. Microbiol. 10, 2944 (2020).

29. Humphreys, C. P. et al. Mutualistic mycorrhiza-like symbiosis in the most ancient group of land plants. Nat. Comm. 1, 103 (2010).

30. Bona, E. et al. Arbuscular mycorrhizal symbiosis affects the grain proteome of Zea mays: a field study. Sci. Rep. 6, 26439 (2016).

31. Fiorilli, V. et al. Omics approaches revealed how arbuscular mycorrhizal symbiosis enhances yield and resistance to leaf pathogen in wheat. Sci. Rep. 8, 9625 (2018).

32. Koide, R. T. \& Lu, X. Mycorrhizal infection of wild oats: maternal effects on offspring growth and reproduction. Oecologia 90, 218-226 (1992).

33. Varga, S., Vega-Frutis, R. \& Kytöviita, M. M. Transgenerational effects of plant sex and arbuscular mycorrhizal symbiosis. New Phytol. 199(3), 812-21 (2013).

34. Martin, F., Kohler, A., Murat, C., Veneault-Fourrey, C. \& Hibbett, D. S. Unearthing the roots of ectomycorrhizal symbioses. Nat. Rev. Microbiol. 14(12), 760-773 (2016).

35. Toruño, T. Y., Stergiopoulos, I. \& Coaker, G. Plant-pathogen effectors: cellular probes interfering with plant defenses in spatial and temporal manners. Annu. Rev. Phytopathol. 54, 419-41. (2016).

36. Franceschetti, $M$. et al. Effectors of filamentous plant pathogens: commonalities amid diversity. Microbiol. Mol. Biol. Rev. 81, e00066-16. (2017).

37. Kohler, A. et al. Convergent losses of decay mechanisms and rapid turnover of symbiosis genes in mycorrhizal mutualists. Nat. Genet. 47, 410-415 (2015). This paper compared the genomes of almost 50 fungi and revealed that, during evolution, all ECM fungi originating from saprotrophic ancestors experienced substantial loss of genes coding for plant cell wall degrading enzymes.

38. Hibbett, D. S., Gilbert, L. B. \& Donoghue, M. J. Evolutionary instability of ectomycorrhizal symbioses in basidiomycetes. Nature 407, 506-508 (2000).

39. Floudas, D. et al. The Paleozoic origin of enzymatic lignin decomposition reconstructed from 31 fungal genomes. Science 336, 1715-9 (2012).

40. Martin, F. et al. Symbiosis insights from the genome of the mycorrhizal basidiomycete Laccaria bicolor. Nature 452, 88-92 (2008). The paper describes the first sequenced genome of a mycorrhizal fungus

41. Pellitier, P. T. \& Zak, D. R. Ectomycorrhizal fungi and the enzymatic liberation of nitrogen from soil organic matter: why evolutionary history matters. New Phytol. 217(1), 68-73 (2018).

42. Peter, M. et al. Ectomycorrhizal ecology is imprinted in the genome of the dominant symbiotic fungus Cenococcum geophilum. Nat. Commun. 7, 12662 (2016).

43. Murat, C. et al. Pezizomycetes genomes reveal the molecular basis of ectomycorrhizal truffle lifestyle. Nat. Ecol. Evol. 2(12), 1956-1965 (2018). 
44. Ferrari S. et al. Oligogalacturonides: plant damage-associated molecular patterns and regulators of growth and development. Front. Plant Sci. 4: 49 (2013).

45. Martino, E. et al. Comparative genomics and transcriptomics depict ericoid mycorrhizal fungi as versatile saprotrophs and plant mutualists. New Phytol. 217, 1213-1229 (2018).

46. Perotto, S., Daghino, S. \& Martino, E. Ericoid mycorrhizal fungi and their genomes: another side to the mycorrhizal symbiosis? New Phytol. 220(4), 1141-1147 (2018).

47. Selosse, M.-A., Schneider-Maunoury, L. \& Martos, F. Time to re-think fungal ecology? Fungal ecological niches are often prejudged. New Phytol. 217, 968972 (2018).

48. Wilson, A. W., Hosaka, K. \& Mueller, G. M. Evolution of ectomycorrhizas as a driver of diversification and biogeographic patterns in the model mycorrhizal mushroom genus Laccaria. New Phytol. 213, 1862-1873 (2017).

49. Albalat, R. \& Cañestro, C. Evolution by gene loss. Nat. Rev. Genet. 17, 379-391 (2016).

50. Chen, E.C.H. et al. High intraspecific genome diversity in the model arbuscular mycorrhizal symbiont Rhizophagus irregularis. New Phytol 220(4), 1161-1171 (2018).

51. Venice, F. et al. At the nexus of three kingdoms: the genome of the mycorrhizal fungus Gigaspora margarita provides insights into plant, endobacterial and fungal interactions. Environ. Microbiol. 22(1), 122-141. (2020).

52. Harrison, M.J. \& van Buuren, M.L. A phosphate transporter from the mycorrhizal fungus Glomus versiforme. Nature 378(6557), 626-629 (1995).

53. Wewer, V., Brands, M. \& Dörmann, P. Fatty acid synthesis and lipid metabolism in the obligate biotrophic fungus Rhizophagus irregularis during mycorrhization of Lotus japonicus. Plant J. 79, 398-412 (2014).

54. Jang, Y. et al. Plants transfer lipids to sustain colonization by mutualistic mycorrhizal and parasitic fungi. Science 356(6343), 1172-1175 (2017). Seminal contribution to the concept of AM fungi as depending on their host plant for lipids

55. Luginbuehl, L. H. et al. Fatty acids in arbuscular mycorrhizal fungi are synthesized by the host plant. Science 356(6343), 1175-1178 (2017). A second insight into the dependence of AM fungi on their hosts for fatty acids

56. Schüßler A. in The Mycota - Fungal Associations (ed. Hock, B.) 77-91 (Springer, Berlin, Heidelberg, 2012).

57. Oldroyd, G.E.D. Speak, friend, and enter: signalling systems that promote beneficial symbiotic associations in plants. Nat. Rev. Microbiol. 11, 252-263 (2013).

58. Delaux, P. M., Radhakrishnan, G. \& Oldroyd, G. Tracing the evolutionary path to nitrogen-fixing crops. Curr. Opin. Plant Biol. 26, 95-99 (2015).

59. Radhakrishnan, G. V. et al. An ancestral signalling pathway is conserved in intracellular symbioses-forming plant lineages. Nat. Plants 6, 1-10 (2020). This extensive analysis of multiple genomes and transcriptomes outlines a conserved set of genes conserved across plant clades that host intracellular symbionts. 
60. Gutjahr, C. \& Parniske, M. Cell and developmental biology of arbuscular mycorrhiza symbiosis. Annu. Rev. Cell Dev. Biol. 29, 593-617 (2013).

61. Genre A, Russo G. Does a common pathway transduce symbiotic signals in plant-microbe interactions? Front. Plant Sci. 7, 9 (2016).

62. Barker, D. G., Chabaud, M., Russo, G. \& Genre, A. Nuclear $\mathrm{Ca}^{2+}$ signalling in arbuscular mycorrhizal and actinorhizal endosymbioses: on the trail of novel underground signals. New Phytol. 214, 533-538 (2017).

63. Bravo, A., York, T., Pumplin, N., Mueller, L. A. \&. Harrison M. J. Genes conserved for arbuscular mycorrhizal symbiosis identified through phylogenomics. Nat. Plants 15208 (2016).

64. Kamel, L. et al. The comparison of expressed candidate secreted proteins from two arbuscular mycorrhizal fungi unravels common and specific molecular tools to invade different host plants. Front. Plant Sci. 8, 124 (2017).

65. Zipfel, C. \& Oldroyd, G. E. Plant signalling in symbiosis and immunity. Nature 543, 328-336 (2017).

66. Akiyama, K., Matsuzaki, K. \& Hayashi, H. Plant sesquiterpenes induce hyphal branching in arbuscular mycorrhizal fungi. Nature 435, 824-827 (2005).

67. Al-Babili, S., Bouwmeester, H. J. Strigolactones, a novel carotenoid-derived plant hormone. Annu. Rev. Plant Biol. 66, 161-86 (2015).

68. Besserer, A., Bécard, G., Jauneau, A., Roux, C. \& Séjalon-Delmas N. GR24, a synthetic analog of strigolactones, stimulates the mitosis and growth of the arbuscular mycorrhizal fungus Gigaspora rosea by boosting its energy metabolism. Plant Physiol. 148, 402-13 (2008).

69. Salvioli A. et al. Symbiosis with an endobacterium increases the fitness of a mycorrhizal fungus, raising its bioenergetic potential. ISME J. 10, 130-144 (2016).

70. Maillet, F. et al. Fungal lipochitooligosaccharide symbiotic signals in arbuscular mycorrhiza. Nature 469, 58-63 (2011). The paper identifies LCOs as the fungal molecules required for AM establishment

71. Genre, A. et al. Short-chain chitin oligomers from arbuscular mycorrhizal fungi trigger nuclear $\mathrm{Ca}^{2+}$ spiking in Medicago truncatularoots and their production is enhanced by strigolactone. New Phytol.198,179-189 (2013). The paper identifies COs as additional fungal molecules required for AM establishment

72. Sun, J. et al. Activation of symbiosis signaling by arbuscular mycorrhizal fungi in legumes and rice. Plant Cell 27, 823-838 (2015).

73. Chabaud, $M$. et al. Chitotetraose activates the fungal-dependent endosymbiotic signaling pathway in actinorrhizal plant species. PLoS One 10, 14(10):e0223149 (2019).

74. He, J. et al. A LysM receptor heteromer mediates perception of arbuscular mycorrhizal symbiotic signal in rice. Mol. Plant 12, 1561-1576 (2019). This paper presents the first description of a bona fide Myc-factor receptor mediating the AM-specific activation of symbiotic signaling.

75. Hohnjec, N., Vieweg, M. F., Pühler, A., Becker, A. \& Küster, H. Overlaps in the transcriptional profiles of Medicago truncatula roots inoculated with two different glomus fungi provide insights into the genetic program activated during arbuscular mycorrhiza. Plant Physiol. 137, 1283-1301 (2005). 
76. Schmitz, A. M. \& Harrison, M. J. Signaling events during initiation of arbuscular mycorrhizal symbiosis. J. Integ. Plant Biol. 56, 250-261 (2014). An outstanding review on the plant-fungal dialogue required for the AM symbiosis

77. Czaja, L. F. et al. Transcriptional responses towards diffusible signals from symbiotic microbes reveal MtNFP-and MtDMI3- dependent reprogramming of host gene expression by arbuscular mycorrhizal fungal lipochitooligosaccharides. Plant Physiol. 159, 1671-1685 (2012).

78. Genre, A., Chabaud, M., Timmers, T., Bonfante, P. \& Barker, D. G. Arbuscular mycorrhizal fungi elicit a novel intracellular apparatus in Medicago truncatula root epidermal cells before infection. Plant Cell 17, 3489-3499 (2005).

79. Gutjahr, C. et al. Presymbiotic factors released by the arbuscular mycorrhizal fungus Gigaspora margarita induce starch accumulation in Lotus japonicus roots. New Phytol. 183(1), 53-61 (2009).

80. Kosuta, S. et al. A diffusible factor from arbuscular mycorrhizal fungi induces symbiosis-specific MtENOD11 expression in roots of Medicago truncatula. Plant Physiol. 131, 952-962 (2003).

81. Miura, C. et al. The mycoheterotrophic symbiosis between orchids and mycorrhizal fungi possesses major components shared with mutualistic plantmycorrhizal symbioses. Mol. Plant Microbe Interact. 31, 1032-1047 (2018).

82. Yuan, Y., et al. The Gastrodia elata genome provides insights into plant adaptation to heterotrophy. Nat. Commun. 9, 1615 (2018).

83. Cope K.R., et al. The ectomycorrhizal fungus Laccaria bicolor produces lipochitooligosaccharides and uses the common symbiosis pathway to colonize Populus roots. Plant Cell 31, 2386-2410 (2019).

84. Sanchez, L. et al. Pseudomonas fluorescens and Glomus mosseae trigger DMI3dependent activation of genes related to a signal transduction pathway in roots of Medicago truncatula. Plant Physiol. 139, 1065-1077 (2005).

85. Weerasinghe, R. R., Bird, D. \& Allen, N. S. Root-knot nematodes and bacterial Nod factors elicit common signal transduction events in Lotus japonicus. Proc. Natl. Acad. Sci. USA 102, 3147-3152 (2005).

86. Fernández-Aparicio, M. et al. Parasitic plant infection is partially controlled through the symbiotic pathways. Weed Res. 50, 76-82 (2009).

87. Skiada, V., Avramidou, M., Bonfante, P., Genre A. \& Papadopoulou. K. K. Symbiotic signalling is at the core of an endophytic Fusarium solani-legume association. bioRxiv 740043; doi: https://doi.org/10.1101/740043 (2019).

88. Genre, A., Ortu, G., Bertoldo, C., Martino, E. \& Bonfante, P. Biotic and abiotic stimulation of root epidermal cells reveals common and specific responses to arbuscular mycorrhizal fungi. Plant Physiol. 149, 1424-1434 (2009).

89. Esseling, J. J., Lhuissier, F. G. \& Emons, A. M. A nonsymbiotic root hair tip growth phenotype in NORK-mutated legumes: implications for nodulation factor-induced signaling and formation of a multifaceted root hair pocket for bacteria. Plant Cell 16, 933-944 (2004).

90. Kobae, Y. et al. Strigolactone biosynthesis genes of rice is required for the punctual entry of arbuscular mycorrhizal fungi into the roots. Plant Cell Physiol. 59, 544-553 (2018). 
91. Genre, A. \& Bonfante, P. Check-in procedures for plant cell entry by biotrophic microbes. Mol. Plant Microbe Interact. 9, 1023-1030 (2007).

92. Mello, A. \& Balestrini R. Recent insights on biological and ecological aspects of ectomycorrhizal fungi and their interactions. Front. Microbiol. 9, 2016 (2018).

93. Zhang, F. et al. The ectomycorrhizal basidiomycete Laccaria bicolor releases a secreted $\beta-1,4$ endoglucanase that plays a key role in symbiosis development. New Phytol. 220: 1309-1321 (2018).

94. Vayssières et al. Development of the poplar-Laccaria bicolor ectomycorrhiza modifies root auxin metabolism, signaling, and response. Plant Physiol. 169, 890-902 (2015).

95. Bonfante, P. et al. The Lotus japonicus LjSym4 gene is required for the successful symbiotic infection of root epidermal cells. Mol. Plant Microbe Interact. 13, 1109-1120 (2000).

96. Perotto, S. et al. Gene expression in mycorrhizal orchid protocorms suggests a friendly plant-fungus relationship. Planta 239, 1337-1349 (2014).

97. Zhao, X. et al. Deep sequencing-based comparative transcriptional profiles of Cymbidium hybridum roots in response to mycorrhizal and non-mycorrhizal beneficial fungi. BMC Genomics 15, 747 (2014).

98. Fournier, J. et al. Remodeling of the infection chamber prior to infection thread formation reveals a two-step mechanism for rhizobial entry into the host legume root hair. Plant Physiol. 167(4), 1233-1242 (2015).

99. Svistoonoff, S., Hocher, V. \& Gherbi, H. Actinorhizal root nodule symbioses: what is signalling telling on the origins of nodulation? Curr. Opin. Plant Biol. 20: 11-18 (2014).

100. Porras-Alfaro, A. \& Bayman, P. Hidden fungi, emergent properties: endophytes and microbiomes. Annu. Rev. Phytopathol. 49, 291-315 (2011).

101. Rosenblueth, M. \& Martínez-Romero, E. Bacterial endophytes and their interactions with hosts. Mol Plant Microbe Interact. 19(8), 827-837 (2006).

102. Mendgen, K. \& Kahn, M. Plant infection and the establishment of fungal biotrophy. Trends Plant Sci. 7(8), 352-356 (2002).

103. Mihwa, Y. \& Valent, B. Communication between filamentous pathogens and plants at the biotrophic interface. Ann. Rev. Phytopathol. 51, 587-611 (2013).

104. Spanu, P. D. \& Panstruga, R. Editorial: biotrophic plant-microbe interactions. Front. Plant Sci. 8, 192 (2017).

105. Tarkka, M. T. et al. OakContigDF159.1, a reference library for studying differential gene expression in Quercus robur during controlled biotic interactions: use for quantitative transcriptomic profiling of oak roots in ectomycorrhizal symbiosis. New Phytol. 199, 529-540 (2013).

106. Duplessis S, Courty PE, Tagu D, Martin F. Transcript patterns associated with ectomycorrhiza development in Eucalyptus globulus and Pisolithus microcarpus. New Phytol 165: 599-611 (2005).

107. Jones, J. D. \& Dangl, J. L. The plant immune system. Nature 444, 323-329 (2006). This is a reference paper for all the studies concerning plant immunity

108. Garcia-Garrido, J. M. \& Ocampo, J. A. Regulation of the plant defence response in arbuscular mycorrhizal symbiosis. J. Exp. Bot. 53, 1377-1386 (2002). 
109. Liu, J. et al. Transcript profiling coupled with spatial expression analyses reveals genes involved in distinct developmental stages of an arbuscular mycorrhizal symbiosis. Plant Cell. 15(9), 2106-23 (2003).

110. Giovannetti, M., Mari, A., Novero, M. \& Bonfante, P. Early Lotus japonicus root transcriptomic responses to symbiotic and pathogenic fungal exudates. Front. Plant Sci. 6, 480 (2015).

111. Martinez-Medina, A. et al. Nitric oxide and phytoglobin PHYTOGB1 are regulatory elements in the Solanum lycopersicum-Rhizophagus irregularis mycorrhizal symbiosis. New Phytol. 223, 1560-1574 (2019).

112. Martinez-Medina, A. et al. Recognizing plant defense priming. Trends Plant Sci. 21(10), 818-822 (2016).

113. Pozo, M. J., \& Azcón-Aguilar, C. Unraveling mycorrhiza-induced resistance. Curr. Opin. Plant Biol. 10, 393-398 (2007).

114. Jung, S., Martinez-Medina, A., Lopez-Raez, J., \& Pozo, M. Mycorrhiza-induced resistance and priming of plant defenses. J. Chem. Ecol. 38, 651-664 (2012).

115. Miozzi, L. et al. Arbuscular mycorrhizal symbiosis: plant friend or foe in the fight against viruses? Front Microbiol. 10, 1238 (2019).

116. Jwa, N. S. \& Hwang, B. K. Convergent evolution of pathogen effectors toward reactive oxygen species signaling networks in plants. Front Plant Sci. 8, 1687 (2017).

117. Chialva, M. et al. Native soils with their microbiotas elicit a state of alert in tomato plants. New Phytol. 220, 1296-1308 (2018).

118. Miyata, K. et al. The bifunctional plant receptor, OsCERK1, regulates both chitin-triggered immunity and arbuscular mycorrhizal symbiosis in rice. Plant Cell Physiol. 55, 1864-1872 (2014).

119. Zhang, X. et al. The receptor kinase CERK1 has dual functions in symbiosis and immunity signalling. Plant J. 81, 258-267 (2015).

120. Shinya, T., Nakagawa, T., Kaku, H. \& Shibuya, N. Chitin-mediated plant-fungal interactions: catching, hiding and handshaking. Curr. Opin. Plant Biol. 26, 64-71 (2015).

121. Zeng, T. et al. LysM effector subverts chitin-triggered immunity to facilitate arbuscular mycorrhizal symbiosis. New Phytol. 225, 448-460 (2020).

122. Sauter, M., \& Hager, A. The mycorrhizal fungus Amanita muscaria induces chitinase activity in roots and in suspension-cultured cells of its host Picea abies. Planta 179, 61-66 (1989).

123. Münzenberger, B., Otter, T., Wüstrich, D. \& Polle, A. Peroxidase and laccase activities in mycorrhizal and non-mycorrhizal fine roots of Norway spruce (Picea abies) and larch (Larix decidua). Can. J. Bot. 75, 932-938 (1997).

124. Pozo, M. J., López-Ráez, J. A., Azcón-Aguilar, C., \& García-Garrido, J. M. Phytohormones as integrators of environmental signals in the regulation of mycorrhizal symbioses. New Phytol. 205, 1431-1436 (2015).

125. Plett, J. M. et al. The effector MiSSP7 of the mutualistic fungus Laccaria bicolor stabilizes the Populus JAZ6 protein and represses JA-responsive genes. Proc. Natl. Acad. Sci. USA 111, 8299 (2014).

126. Tisserant, E. et al. Genome of an arbuscular mycorrhizal fungus provides insight into the oldest plant symbiosis. Proc. Natl. Acad. Sci. USA 110, 20117-20122 (2013). 
127. Lin, K. et al. Single nucleus genome sequencing reveals high similarity among nuclei of an endomycorrhizal fungus. PLoS Genet. 10, e1004078 (2014).

128. Zeng, T. et al. Host- and stage-dependent secretome of the arbuscular mycorrhizal fungus Rhizophagus irregularis. Plant J. 94, 411-425 (2018).

129. Kloppholz, S., Kuhn. H. \& Requena, N. A secreted fungal effector of Glomus intraradices promotes symbiotic biotrophy. Curr. Biol. 21, 1204-1209 (2011).

130. Voß, S., Betz, R., Heidt, S., Corradi, N. \& Requena, N. RiCRN1, a crinkler effector from the arbuscular mycorrhizal fungus Rhizophagus irregularis, functions in arbuscule development. Front. Microbiol. 9, 2068 (2018).

131. Casarrubia, S. et al. The hydrophobin-like OMSSP1 may be an effector in the ericoid mycorrhizal symbiosis. Front. Plant Sci. 9, 546. (2018).

132. Teixeira, P. J., Colaianni, N. R., Fitzpatrick, C. R. \& Dangl, J. L. Beyond pathogens: microbiota interactions with the plant immune system. Curr. Opin. Microbiol. 49:7-17 (2019).

133. Hynson, N. A. et al. in Mycoheterotrophy (ed. Merckx, V.) 297-342 (Springer, New York, 2013).

134. Balzergue, C., Chabaud, M., Barker, D. G., Bécard, G. \& Rochange, S. F. High phosphate reduces host ability to develop arbuscular mycorrhizal symbiosis without affecting root calcium spiking responses to the fungus. Front. Plant Sci. 4, 426 (2013).

135. Muller, L. M. \& Harrison, M. J. Phytohormones, miRNAs, and peptide signals integrate plant phosphorus status with arbuscular mycorrhizal symbiosis. Curr. Opin. Plant Biol. 50, 132-139 (2019).

136. Desirò, A. et al. Mollicutes-related endobacteria thrive inside liverwortassociated arbuscular mycorrhizal fungi. Environ. Microbiol. 15, 822-836 (2013).

137. Genre, A., \& Bonfante, P. in The Mycota: Fungal Associations, 2nd Edn, (ed. Hock, B.) 39-49 (Springer, Berlin, 2012).

138. Luginbuehl, L. H. \& Oldroyd, G. E. Understanding the arbuscule at the heart of endomycorrhizal symbioses in plants. Curr. Biol. 27, R952-R963 (2017).

139. Bonfante, P. At the interface between mycorrhizal fungi and plants: the structural organization of cell wall, plasma membrane and cytoskeleton. In: Hock B. (ed) Fungal Associations. The Mycota vol 9. Springer, Berlin, Heidelberg (2000).

140. Ivanov, S., Austin, J., Berg, R.H. \& Harrison, M. J. Extensive membrane systems at the host-arbuscular mycorrhizal fungus interface. Nat. Plants 5, 194-203 (2019).

141. Roth, R.et al. Arbuscular cell invasion coincides with extracellular vesicles and membrane tubules. Nat. Plants 5, 204-211 (2019).

142. Bender, S.F., Wagg, C. \& van der Heijden, M. G. An underground revolution: biodiversity and soil ecological engineering for agricultural sustainability. Trends Ecol. Evol. 31, 440-452 (2016).

143. Mello, A., Zampieri, E. \& Balestrini, R. in Plant Microbes Symbiosis: Applied Facets (ed. Arora, N. K.) 315-326 (Springer, New Delhi, 2015).

144. Kipfer, T., Moser, B., Egli. S., Wohlgemuth, T. \& Ghazoul J. Ectomycorrhiza succession patterns in Pinus sylvestris forests after stand-replacing fire in the Central Alps. Oecologia 167, 219-228 (2011). 
145. Khosla, B. \& Reddy, M. S. Response of ectomycorrhizal fungi on the growth and mineral nutrition of Eucalyptus seedlings in bauxite mined soil. Am-Eurasian J Agric Environ Sci. 3, 123-126 (2008).

146. Sousa, N. R., Franco, A. R., Oliveira, R. S. \& Castro, P. M. L. Ectomycorrhizal fungi as an alternative to the use of chemical fertilisers in nursery production of Pinus pinaster. J. Environ. Manag. 95, S269-S274 (2012).

147. Oliveira, R. S., Franco, A. R. \& Castro, P. M. L. Combined use of Pinus pinaster plus and inoculation with selected ectomycorrhizal fungi as an ecotechnology to improve plant performance. Ecol. Eng. 43, 95-103 (2012).

148. Zhang, H. H., Tang, M., Chen, H. \& Zheng, C. L. Effects of inoculation with ectomycorrhizal fungi on microbial biomass and bacterial functional diversity in the rhizosphere of Pinus tabulaeformis seedlings. Eur. J. Soil Biol. 46, 55-61 (2010).

149. Oliveira, R. S., Franco, A. R., Vosátka, M. \& Castro, P. M. L. Management of nursery practices for efficient ectomycorrhizal fungi application in the production of Quercus ilex. Symbiosis 52, 125-131 (2010).

150. Bauman, J. M., Keiffer, C. H., Hiremath, S. \& McCarthy, B. C. Soil preparation methods promoting ectomycorrhizal colonization and American chestnut Castanea dentate establishment in coal mine restoration. J. Appl. Ecol. 50, 721729 (2013).

151. Danell, E. \& Camacho, F. J. Successful cultivation of the golden chanterelle. Nature 385, 303 (1997).

152. Mello, A. in Edible ectomycorrhizal mushrooms. Soil biology vol.34 (eds Zambonelli, A. \& Bonito, G. M.) 73-81 (Springer, Berlin, Heidelberg, 2012).

153. Murat, $C$. Forty years of inoculating seedlings with truffle fungi: past and future perspectives. Mycorrhiza 25, 77-81 (2015).

154. Zambonelli, A., lotti, M. \& Murat, C. True truffle (Tuber spp.) in the world. (Springer, 2016).

155. Ceballos, I. et al. The in vitro mass-produced model mycorrhizal fungus, Rhizophagus irregularis, significantly increases yields of the globally important food security crop cassava. PLoS ONE 8, e70633 (2013).

156. Rodriguez, A. \& Sanders, I. R. The role of community and population ecology in applying mycorrhizal fungi for improved food security. ISME J. 9, 1053-1061 (2015).

157. Hijri, M. Analysis of a large dataset of mycorrhiza inoculation field trials on potato shows highly significant increases in yield. Mycorrhiza 26, (2016).

158. Rocha, l. et al. Seed coating with arbuscular mycorrhizal fungi for improved field production of chickpea. Agronomy 9, 471-482 (2019).

159. Berruti, A., Lumini, E., Balestrini, R. \& Bianciotto V. Arbuscular mycorrhizal fungi as natural biofertilizers: let's benefit from past successes. Front. Microbiol. 6, 1559 (2016).

160. Chen, M., Arato, M., Borghi, L., Nouri, E. \& Reinhardt, D. Beneficial services of arbuscular mycorrhizal fungi - from ecology to application. Front. Plant Sci. 9, 1270 (2018).

161. Lehmann, A., Veresoglou, S. D., Leifheit, E. F. \& Rillig, M. C. Arbuscular mycorrhizal influence on zinc nutrition in crop plants - a meta-analysis. Soil Biol \& Biochem. 69, 123-131 (2014). 
162. Bona, E. et al. Arbuscular mycorrhizal fungi and plant growth-promoting pseudomonads improve yield, quality and nutritional value of tomato: a field study. Mycorrhiza 27, 1-11 (2017).

163. Torres, N., Antolin, M. C. \& Goicoechea, N. Arbuscular mycorrhizal symbiosis as a promising resource for improving berry quality in grapevines under changing environments. Front. Plant Sci. 9, 18 (2018).

164. Ryan, M.H. \& Graham, J.H. Little evidence that farmers should consider abundance or diversity of arbuscular mycorrhizal fungi when managing crops. New Phytol. 220, 1092-1107 (2018).

165. Rillig, M. C. et al. Towards an integrated mycorrhizal technology: harnessing mycorrhizae for sustainable intensification in agriculture. Front. Plant Sci. 7, 1625 (2016).

166. Cavagnaro, T. R., Bender, S. F., Asghari, H. R. \& van der Heijden M. G. A. The role of arbuscular mycorrhizas in reducing soil nutrient loss. Trends Plant Sci. 20, 283-290 (2015).

167. Rillig, M. C. et al. Why farmers should manage the arbuscular mycorrhizal symbiosis. New Phytol. 222, 1171-1175 (2019).

168. DeClerck, F. A. J. et al. Agricultural ecosystems and their services: the vanguard of sustainability? Curr. Opin. Environ. Sust. 23, 92-99 (2016).

169. Janos, D. P. Plant responsiveness to mycorrhizas differs from dependence upon mycorrhizas. Mycorrhiza 17, 75-91 (2007).

170. Kameoka, $\mathrm{H}$. et al. Stimulation of asymbiotic sporulation in arbuscular mycorrhizal fungi by fatty acids Nat. Microbiol. 4, 1654-1660 (2019). This seminal research broke the dogma of unculturability of arbuscular mycorrhizal fungi by demonstrating that the addition of fatty acids to the medium allows their asexual reproduction in axenic culture.

171. Sugiura, Y. et al. Myristate as a carbon and energy source for the asymbiotic growth of the arbuscular mycorrhizal fungus Rhizophagus irregularis. bioRxiv (2019).

172. Sosa-Hernández, M. A., Leifheit, E. F., Ingraffia, R. \& Rillig, M. C. Subsoil arbuscular mycorrhizal fungi for sustainability and climate-smart agriculture: a solution right under our feet? Front. Microbiol. 10, 744 (2019).

173. Volpe, V. et al. Short chain chito-oligosaccharides promote arbuscular mycorrhizal colonization in Medicago truncatula. Carbohydrate Polymers 229, 115505 (2020). This research shows that the perception of short chain chitooligosaccharides stimulates AM colonization and arbuscule development, providing crucial evidence in favor of the role of these soluble molecules as positive elicitors of symbiotic responses in the host plant.

174. Daghino, S., Martino, E., \& Perotto, S. Model systems to unravel the molecular mechanisms of heavy metal tolerance in the ericoid mycorrhizal symbiosis. Mycorrhiza 26, 263-274. (2016).

175. Ruytinx, J. et al. in Molecular Mycorrhizal Symbiosis (ed. Martin, F.) 277-298 (John Wiley \& Sons, Inc. Hoboken, NJ, 2016).

176. Backhouse, G. Are our orchids safe down under? A national assessment of threatened orchids in Australia. Lankesteriana 7, 28-43 (2007).

177. Rasmussen, H. N. Recent developments in the study of orchid mycorrhiza. Plant Soil 244, 149-163 (2002). 
178. Reiter, N., Lawrie, A. C. \& C. Linde, C. C. Matching symbiotic associations of an endangered orchid to habitat to improve conservation outcomes. Ann. Bot.122, 947-959 (2018).

179. McCormick, M. K., Dennis, F., Whigham, D. F. \& Canchani-Viruet, A. Mycorrhizal fungi affect orchid distribution and population dynamics. New Phytol. 219, 1207-1215 (2018). 


\section{Box 1. Main cellular features of ectomycorrhiza, arbuscular, orchid and ericoid}

mycorrhiza

The majority of mycorrhizal interactions belong to the four types illustrated in the scheme, which are also the most studied. In arbuscular mycorrhiza, hyphae originating from soil germinating spores contact the epidermal cell of host lateral roots through a flattened, often branched structure called the hyphopodium ${ }^{79,90}$. The hyphopodium and epidermal cell walls attach in an unclear process of softening and interweaving ${ }^{137}$. Penetrating hyphae then develop, cross the outer root cell layers with diverse colonization patterns that include the formation of loose intracellular coils and branched hyphae, and finally reach inner cortical cells, where they originate tree-like arbuscules ${ }^{138}$. Intracellular hyphae and arbuscules are always separated from the plant cell cytoplasm by an apoplastic interface surrounded by a perifungal membrane, a specialized extension of the host plasma membrane (in green). The periarbuscular interface is believed to be the main site of nutrient exchange ${ }^{139}$, possibly facilitated by tubular expansions increasing the exchange surface ${ }^{140,141}$. In ericoid mycorrhiza, hyphae penetrate the thick epidermal cell walls of Ericaceae roots without the development of apparent adhesion structures. Dense hyphal coils are then produced inside each epidermal cell, also in this case surrounded by an interface compartment (green) and an extension of the plant membrane ${ }^{8}$.

In orchid mycorrhiza, symbiotic fungi may develop in germinating seeds and seedling roots, but the best described colonization process is in protocorms, the embryonic tuber-shaped structures that develop upon seed germination. In this case, hyphae penetrate epidermal hair cells and reach the cortical parenchyma where they form large hyphal coils, called pelotons ${ }^{8}$, within a membrane-delimited symbiotic interface.

In ectomycorrhiza, sub-apical epidermal cells of emerging lateral roots are targeted by soil-borne hyphae. Their proliferation generates a pseudoparenchymatous tissue known as the sheathing mantle, engulfing the whole root tip ${ }^{8}$. The mantle's inner hyphae further develop between epidermal cells reaching different depths into the cortical tissue (depending on the host plant). Such intraradical hyphae never 
penetrate the cell lumen, and the so-called Hartig net forms an intercellular interface (green).

\section{Box 2. Towards a translational research}

Mycorrhizal fungi have become acknowledged as potential beneficial drivers of an upcoming microbial revolution in the age of the microbiota, along with $\mathrm{N}$-fixing bacteria, other plant growth promoting microorganisms and endophytes ${ }^{142}$.

Due to their broad diversification, mycorrhizal fungi have been successfully applied in very different sectors. In particular, ectomycorrhizas (ECM) have massive potential in forest management ${ }^{143}$, including regeneration after stand-replacing forest fires ${ }^{144}$ and ecological restoration of mine sites ${ }^{145}$. ECM fungal inocula have been used for seedling production of both conifers ${ }^{146,147,148}$ and broad-leaved trees ${ }^{149,150}$. Furthermore, a growing number of applicative studies have focused on ECM fungi that produce worldwide appreciated delicacies such as boletes, chantarelles and truffles $^{151,152,153}$. The inoculation of host tree seedlings with black truffle (Tuber melanosporum Vittad.) was so successful that over $80 \%$ of black truffle production occurs in orchards in France ${ }^{154}$.

The urgent demand for food safety and low-impact, sustainable agricultural practices offers a broad field of application for mycorrhizal interactions. In this respect, arbuscular mycorrhizal (AM) fungi have the strongest potential, owing to their ability to colonize the majority of crop plants, and their positive effects on plant productivity $^{31,155-160}$ and crop quality ${ }^{161,162,163}$. However, results on the benefits provided by AM fungi to host plants obtained in greenhouses may not directly be applicable in the field. As commented on in a recent field meta-analysis study ${ }^{164}$, a benefit in terms of increased yield is not often evident, especially when cereals are considered. It is also worth noting that AM fungi may also contribute to ecosystem functions such as soil aggregation ${ }^{165}$ and reduced nutrient losses ${ }^{166}$. In addition, the reduced need for fertilizers directly influences the profitability and environmental impact of AM-based agricultural practices, even in the absence of a net yield increase. As previously advocated ${ }^{167}$, new production systems must be developed where the benefits for the host plant and the ecosystem services provided by 
mycorrhizal symbionts and other beneficial microorganisms are maximized to support sustainable agriculture ${ }^{142,168 .}$

In the face of this great potential, the application of AM fungi in agroecosystems poses some technical challenges. Firstly, environmental variables can substantially impact the beneficial effects of $A^{169}$. Secondly, obligate biotrophy of AM fungi has been a major limitation to large scale inoculum production. Feeding AM fungi with lipids ${ }^{170,171}$ opens new opportunities for massive in vitro production of pure inocula. Lastly, the role of beneficial plant-fungus interactions has been overlooked for centuries by plant breeders, leading to crop varieties that have a high performance in fertilized soils, but are not particularly prone to AM colonization ${ }^{172}$. A novel approach has recently been proposed, based on the demonstration that plant treatments with exogenous Myc-factors (such as short-chain chitooligosaccharides ) promote AM establishment ${ }^{173}$. Field treatments with such AM fungal signals could facilitate root colonization by both native and inoculated AM fungi.

Despite the specific applied perspectives of each type of mycorrhizal fungi, common challenges are emerging. Germplasm collection of fungal isolates has to increase, inoculum production and formulation must be optimized, and natural variation has to be investigated to identify the best performing plant-fungal combinations. Moreover, the impact of fungal microbiota on the beneficial effects of mycorrhizas is far from being fully understood ${ }^{11}$. Finally, the feasibility of large-scale mycorrhizal plant production and development of technologies in developing countries are crucial aspects that have to be addressed.

\section{Box 3. Research themes and open questions}

\section{Origin and distribution of arbuscular mycorrhizal fungi}

Phylogenomics has demonstrated the origin and evolutionary trends of ectomycorrhizal fungi (ECM), whereas the origin of fungi forming arbuscular mycorrhizas (AM) remains unclear. In particular:

- Do arbuscular mycorrhizal fungi (Glomeromycotina) originate from saprotrophic ancestors? 
- How common are Mucoromycotina interactions with extant plant lineages? What was their role in plant terrestrialization?

- Is the available set of fossil data representative of the global process of mycorrhiza-assisted plant establishment on land?

\section{Signalling in mycorrhizas}

Despite the recent progress in the identification of the genetic and molecular determinants of signal exchange in different mycorrhizal types, several questions remain open:

- Which genes and regulatory networks are involved in the production of short chito- and lipochito-oligosaccharides in AM fungi? Do mycorrhizal fungi possess specific acyltransferases for LCO biosynthesis similarly to rhizobia?

- How common is lipo-chitooligosaccharide-based signalling in ECM fungi? Is it conserved in ECM fungi interacting with plants that have lost the common symbiotic signaling pathway?

- What signals are exchanged between partners in ericoid mycorrhizas (ERM) and orchid mycorrhizas (ORM)? Do ERM and ORM fungi produce chitinrelated Myc-factors?

- What is the perception mechanism of strigolactones in AM fungi? Are other plant molecules involved in symbiotic signaling?

- What is the function of 'symbiotic' genes in non-mycorrhizal plants and/or in non-mycorrhizal interactions?

\section{Towards functional symbioses}

After signaling their presence to the host plant, mycorrhizal fungi must be able to colonize the plant tissues without triggering the host defence responses in order to establish a functional mutualistic symbiosis. Key questions remain in this area:

- How do AM fungi colonize plant tissues with their limited CAZyme equipment? 
- How do endomycorrhizal fungi mitigate plant defence once inside the host cells? In particular, how do ERM fungi prevent triggering plant defence in spite of the strong CAZyme upregulation during symbiosis?

- Are there similarities - due to convergent evolution - in the mechanisms of action of effectors in the different mycorrhizal systems? Or are lineagespecific functions more prominent?

- Are systemic signals that underpin plant stress response conserved in the different mycorrhizal types?

- How do plants modulate their susceptibility to mycorrhizal fungi in response to environmental conditions, such as nutrient availability?

\section{Figure legends}

Fig. 1. Major mycorrhizal types. al The major morphological distinctions between ectomycorrhizas (ECM), mostly involving trees and shrubs, and endomycorrhizas, which include ericoid mycorrhizas (ERM) (restricted to Ericaceae), orchid mycorrhizas (ORM) (limited to Orchidaceae) and the more widespread arbuscular mycorrhizas (AM). b| The reciprocal exchange of nutrients in the mutualistic mycorrhizal symbiosis is shown. In AM, organic carbon fixed by the plant through photosynthesis is transferred to the fungus in exchange for soil-derived water and inorganic compounds containing phosphorus, nitrogen, sulfur and other essential nutrients. c| Some fungal species such as Russula sp. develop different types of mycorrhizal interactions: ECM with a tree species and ORM with an orchid,. d| The opposite situation is shown, where a single plant host (like poplar) can develop both AM and ECM. e| The formation of a common mycorrhizal network within plant communities is shown, where the hyphae of fungal individuals colonize different plants, allowing the exchange of nutrients and signals. 
Fig. 2. Arbuscular mycorrhiza symbiosis in extant bryophytes. al The transverse section of a Conocephalum sp. thallus reveals arbuscular mycorrhiza (AM) fungal structures in the central parenchyma underlying the photosynthetic chlorenchyma. b| A higher magnification shows the details of arbuscule morphology, with large trunk hyphae originating thinner branches. c| Transmission electron microscopy shows that such intracellular hyphae are surrounded by the invaginated host membrane, producing an interface compartment, a constant feature of all endomycorrhizas. Scale bars, $150 \mu \mathrm{m}$ (part a), $15 \mu \mathrm{m}$ (part b) and $0.25 \mu \mathrm{m}$ (part c). Images are reproduced from ref. with permission.

Fig. 3. Unique and common traits in mycorrhizal interactions. The scheme illustrates how the plant common symbiotic signaling pathway (CSSP) underpins all three endomycorrhizas (arbuscular mycorrhizas (AM), ericoid mycorrhizas and orchid mycorrhizas); a limited equipment of fungal carbohydrate-active enzymes (CAZymes) represents a common trait of AM and ectomycorrhizas, whereas microbe-associated molecular patterns (MAMP)- and effector-mediated signaling is found in all mycorrhizas. Notably, the one symbiosis relying on all three features (AM) involves Glomeromycotina, the only obligate biotrophs among mycorrhizal fungi. Brown circlesrepresent the relative abundance of each type of mycorrhizal interaction across plant lineages. 

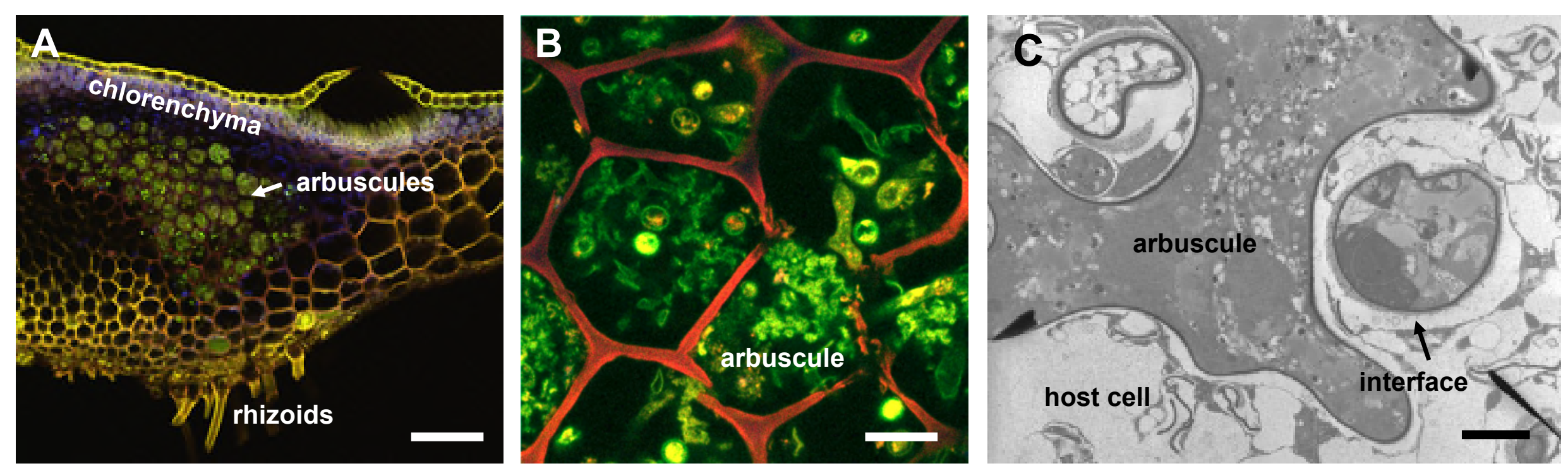


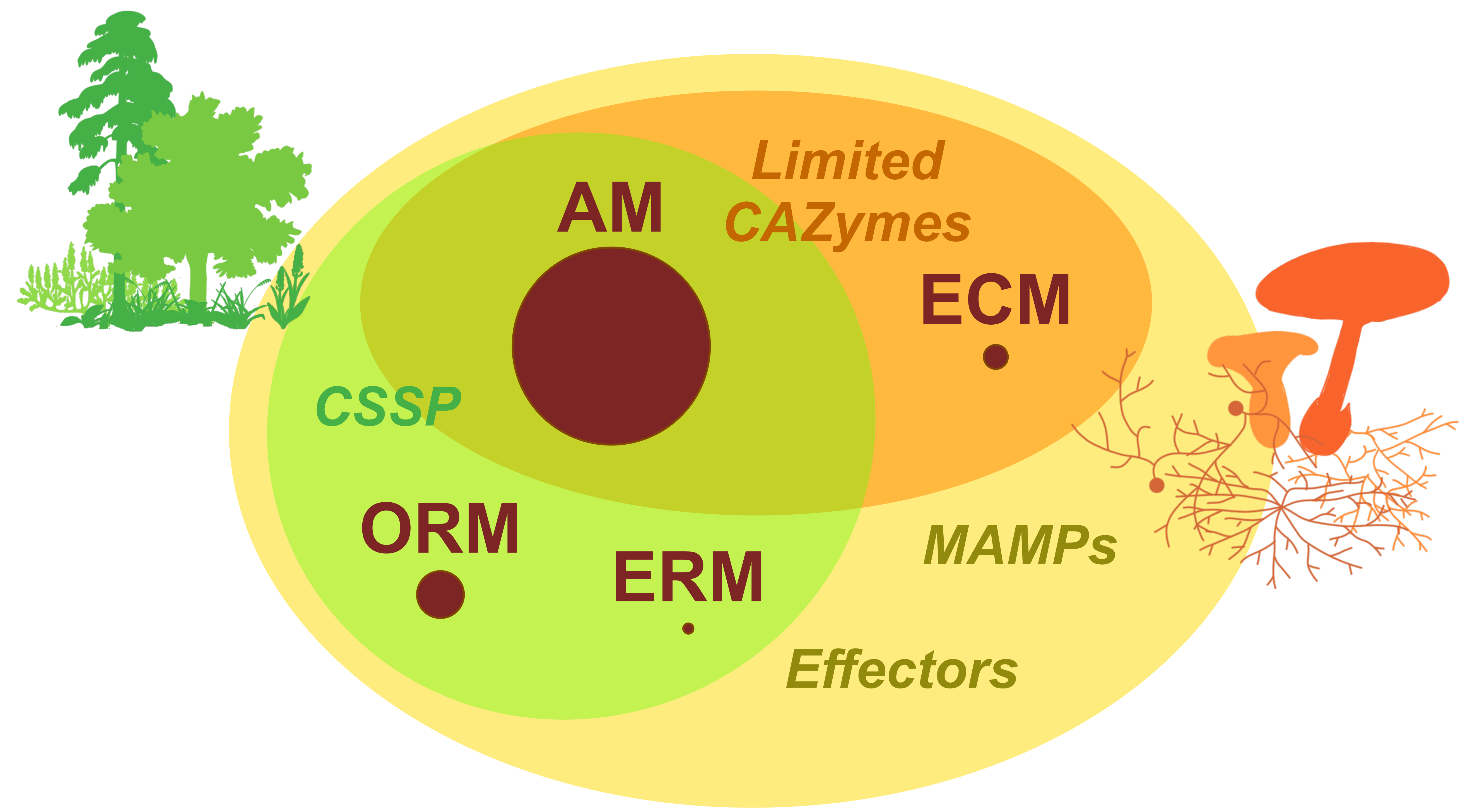


A

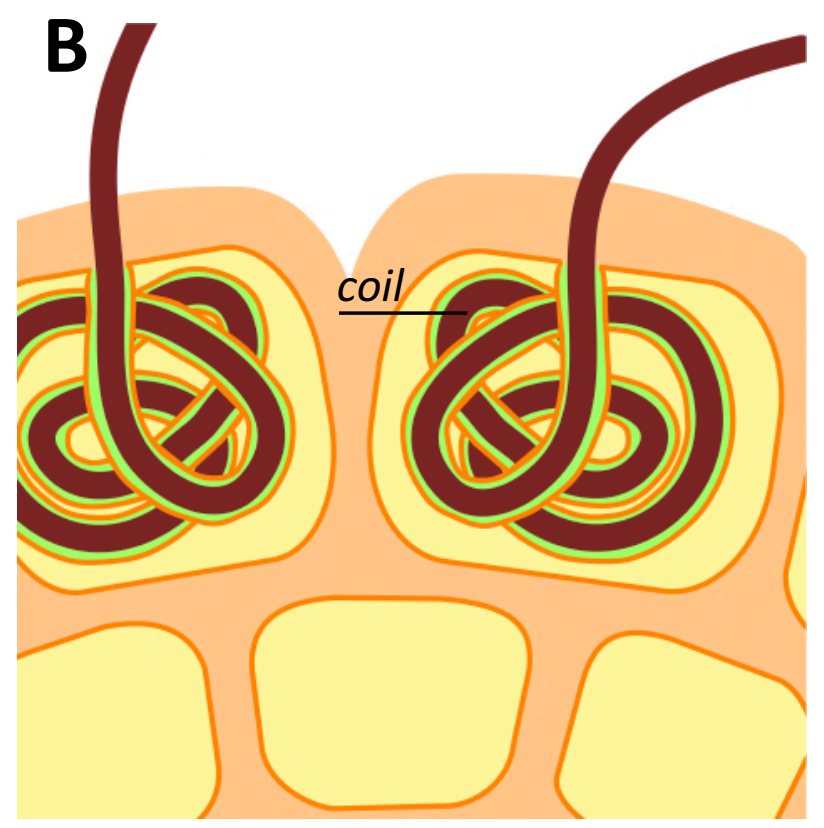

C
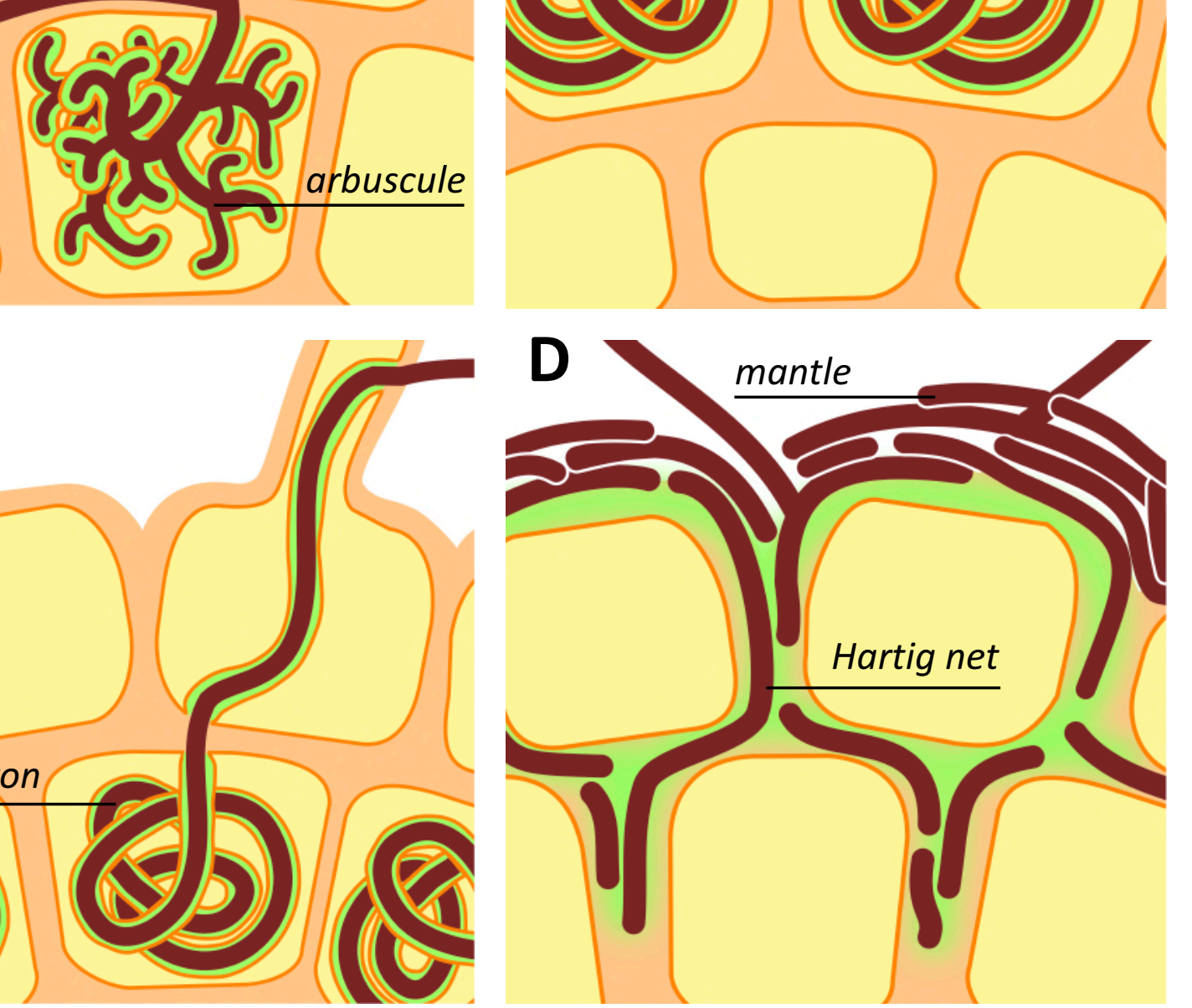
- Reforestation

- Fruibody production

- Landscape / Leisure

- Arboriculture

- Phytostabilization

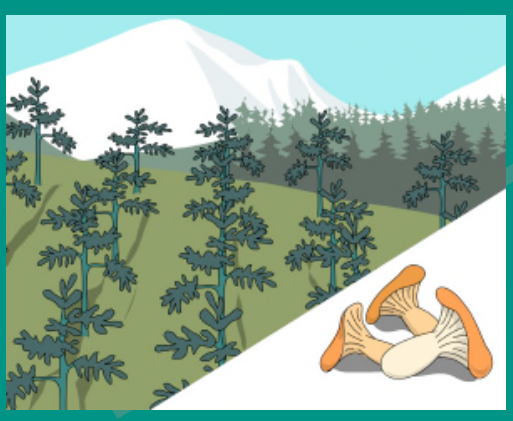

- Bioremediation

- Berry production

- Flower production

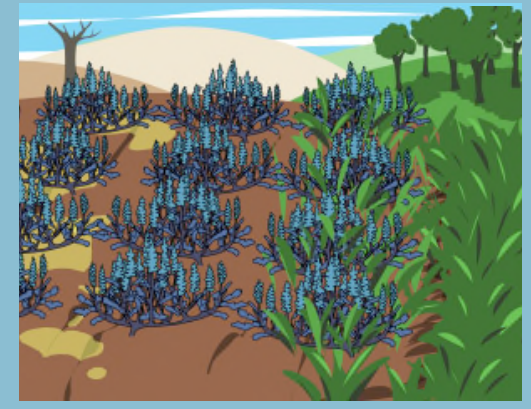

- Conservation

- Traditional medicine

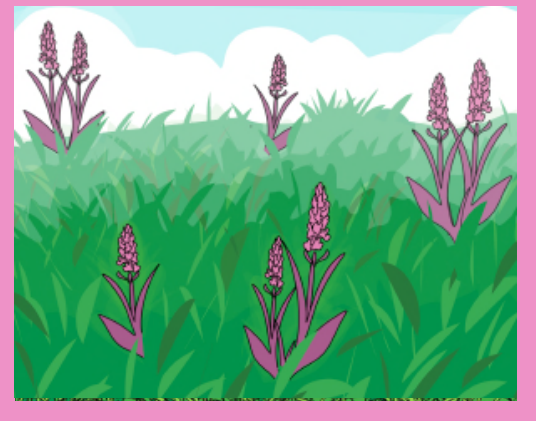

- Crop production

- Fodder production

- Fruit production

- Horticulture

- Phytoremediation

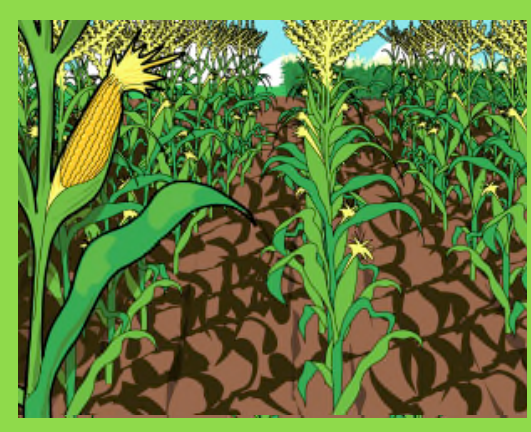

